\title{
The Soil-Pile Dynamic Interaction Effect on Bridges with Slab- Beam Deck by Using Finite Element Method
}

\author{
Moein Zargar ${ }^{1 *}$, Amir Kheirkhah ${ }^{2}$, Seyed Navid Ebrahimzadeh ${ }^{3}$ \\ ${ }^{1}$ Design Expert in Engineering Department, ArchCo (Arshit Armeh) Consulting Engineers, Isfahan, IRAN \\ ${ }^{2}$ Department of Civil Engineering, Azad University of Lenjan \\ ${ }^{3}$ Design Expert in Engineering Department, ArchCo (Arshit Armeh) Consulting Engineers, Isfahan, IRAN
}

*Corresponding Author: Moein Zargar, Design Expert in Engineering Department, ArchCo (Arshit Armeh) Consulting Engineers, Isfahan, IRAN

\begin{abstract}
Accurate understanding of structures during earthquakes has always been a challenge for engineers. Increasing awareness in this area can lead to improved regulations and safer designs. One of the most important steps in understanding this behavior is understanding the behavior of both soil and structures during an earthquake. Soil due to nonlinear behavior changes the seismic response of the structure and the soil movement is affected by the presence of the structure. Influence of Structure Response on Nonlinear Soil Behavior and in contrast, the type of response and behavior of the underlying soil layer due to the presence of structure is called soil-structure interaction phenomenon. The effects of soil-structure interaction and the significance of the changes in the seismic response of the structure through the analysis of this behavioral set are generally irrelevant. These effects may increase or decrease the seismic response of the structure or other seismic parameters due to earthquake force. It is also possible that as these changes occur, the distribution of power in the members of the lateral resistance system may also change (decrease or increase) and may affect their safety, efficiency or durability. In this study, the effect of soil-pile dynamic interaction on slab-beam deck bridges with finite element method is investigated. For this purpose, using Abacus finite element software, a bridge with reinforced concrete slab deck and deep foundations, both with and without interaction effects, have been investigated. Stresses, strains, displacements and acceleration of bridge deck were studied in this study. The results showed that considering soil interaction and PI increased the maximum stress of the whole bridge set in the studied model. However, closer studies show that soil and structure interactions reduce stress on deck and bridge foundations and increase the amount of stress in the wake and pile group.
\end{abstract}

\section{INTRODUCTION}

One way to study the static and dynamic performance of soil structures in geotechnical engineering is to use numerical methods. Given the problems in numerical simulation of these steps in terms of complex soil behaviors and different behavioral models, the presence of water in the soil and the interaction of soil and structure is still a topic of discussion in the world. And their results are stated.

In 2019, Soltani investigated the seismic behavior of diagonal reinforced concrete bridges located on a hard clay bed, under the influence of earthquakes in the near field, taking into account the interaction of soil and structure. The aim of this study was to investigate the behavior of diagonal highway bridges with and without considering the effects of soil and structure interaction under the effects of near-earth fault movements. A series of nonlinear time history analyzes were performed using seven high-intensity pulse records and three components (two horizontal components and one vertical component) on a bridge in California with a prefabricated reinforced concrete box and using the results. The result, the effect of turb angle and how to model the base end conditions and abutments on various applications such as displacement and side drift of the base column, deck period and deformation of shear keys were evaluated. It has been found that most applications are sensitive to increases in the angular turb angle of the abutment and will often have an increasing trend with increasing this angle. On the other hand, considering the effect of soil and structure interaction in modeling, in most cases, led to a decrease in demand compared to the conditions for considering a solid foundation [1]. 
In 2019, Siahi investigated the effect of interaction effects between soil and structure and infilled frame on the static and dynamic response of structures. In this paper, the evaluation of soil and structural interaction criteria and the impact of intermediates using the FEMA440 guidelines on structural models 3, 8, 15, 3, 6 and 6 spans as representing short, medium and long buildings located in an area with relative high seismic risk have been selected. The results indicate the high impact of soil-structure interaction and infilled frame impact that has been investigated using rod method in this study [2].

In 2019, Asgari investigated the effect of soil-structure interaction on the modal specifications of large-scale wind turbines. In this study, the interaction of soil and structure using CONAN software based on cone model has been modeled and the impact of 10 different soil types that cover all four types of soil classified in Iran 2800 standard, on the fluctuations of wind turbine 5.1MW reference. The interaction calculated by CONAN software is applied to the wind turbine tower as support conditions and structural analysis is performed in SAP2000 software. The results of modal analysis and comparison of changes in the natural frequency of the structure in different modes of interaction indicate the significant effect of soil type on the change in the natural frequencies of the structure; So that the frequency change for the first mode of oscillation varies up to $81 \%$, depending on the type of soil, and the lower the soil stiffness, the higher the percentage of frequency changes. Also, the rate of participation of higher modes in different modes of interaction varies and with decreasing soil stiffness, the percentage of impact of higher modes increases and the number of effective modes decreases [3].

In 2019, Shayanfar evaluated the effect of soil and structural interaction phenomenon on the fragility curve of three-span concrete bridge. In this study, the responses of different components of a threespan concrete bridge due to non-linear dynamic analysis and their corresponding fragility curves in two modes without interaction and interaction of soil with pile group foundation were compared with each other. The results of this study show that considering the effect of soil and structure interaction causes a significant change in seismic response and fragility curves of some bridge components such as columns as well as the transverse displacement of the deck. At the same time, considering this phenomenon does not have much effect on the resistant state of abutments [4].

In 2019, Asghari and Jani studied the numerical behavior of the seismic response of the pile group by considering the effects of the structure-soil-pile interaction. In this study, the behavior of foundations based on piles that has been studied under vertical loads and seismic loads under the influence of the distance of piles in the pile group has been investigated. The present study focused on the finite element method of seismic behavior of micro piles. In this study, the vertical lateral boundaries of the soil are modeled in such a way that the reflection of the waves reaching the inside of the model is eliminated. Parametric studies have been performed on independent variables such as the frequency content of the input motion, soil characteristics, and the distance of the aggregates. The results of this study show that with increasing distance between micro piles, the response of micro piles generally increases. The results of this study show that the ratio of S/D (ratio of the distance of the pile to the diameter of the pile) affects the range of dynamic response and internal forces in the fall. Based on the results, it can be said that the maximum displacement at the top of the piles from $61 \mathrm{~cm}$ for clay soil to $48 \mathrm{~cm}$ for sandy soil at $\mathrm{S} / \mathrm{D}=10$, which indicates The decrease is $28 \%$ with increasing soil stiffness [5].

In 2018, Eftekhari and Safi examined the effect of soil shear parameters on soil and structure interaction in concrete structures of the fourth edition of Standard 2800. In this study, by examining 5 and 10 story concrete structures with lateral strength system moment frame in Type III structures based on standard classification 2800, four editing and modeling of soil and structure system using Ansis and MATLAB software and concrete members design. Based on the output of the software, it has been concluded that in terms of soil-structure interaction analysis, it will cause new deformations in different members, which will result in a reduction or increase in the area and weight of the reinforcement used. Also, in general, the effects of soil interaction increase the rotation time of the structure and reduce the base shear and displacement [6]. 
The Soil-Pile Dynamic Interaction Effect on Bridges with Slab-Beam Deck by Using Finite Element Method

\section{Materials AND Methods}

\subsection{Research Methods}

In this study, a 4-span bridge with a length of 68 meters and a width of 21 meters with a column height of 11 meters was loaded by the Northridge earthquake method with finite element method. The simulation was performed by the powerful Abaqus/Explicit finite element software. Loading is based on Journal No. 139 (IRAN's Rules for loading bridge). Each base is modeled by a deep foundation with 9 concrete piles. Once the piles were placed on a rock bed and once the piles were just buried in the ground. Finally, the results of the two models were compared and the results were extracted. The bridge model in Abacus software in the part section was modeled in three-dimensional form. The bridge model was modeled with 4 openings. The deck of the bridge was modeled with a length of 68 meters and a width of 21 meters. The columns were modeled with a height of $11(\mathrm{~m})$ and the cross section of the columns were $914 \times 914(\mathrm{~mm})$ with $1219 \times 914(\mathrm{~mm})$ beams on them which columns stand on the $914 \times 2134 \times 2134(\mathrm{~mm})$ concrete foundations and the middle columns are $2750 \times 2750 \times 914(\mathrm{~mm})$. The model of the pile with a diameter of 1 meter and a height of 4 meters with 3D style and reinforcement included was modeled. The deck rebar's model was modeled separately with the Truss element and placed as an image section side by side in the ASSMBLY. The beams rebar's are 19 meters long and are connected by $305 \times 820 \mathrm{~mm}$ spacing with $305(\mathrm{~mm})$ intervals. The columns reinforcement is 9300 meters long with $812 \times 812(\mathrm{~mm})$ stirrup with $305(\mathrm{~mm})$ distances. The reinforcement of the connecting beams of the foundations which connected foundations to each other are with a length of 15.3 meters, which stirrups are $300 \times 300(\mathrm{~mm})$ with distances of $270(\mathrm{~mm})$.

\subsection{Properties of Materials}

The mechanical properties of the materials used in the modeling were defined in the table below (table1) and applied to the models. The steel model was defined as elastoplastic with the properties given in the table below. The concrete model was also defined as CDP.

Table1. Properties of materials used in research

\begin{tabular}{|c|c|c|c|c|c|c|c|}
\hline Materials & $\begin{array}{c}\text { Density } \\
\mathrm{Kg} / \mathrm{m} 3\end{array}$ & $\begin{array}{c}\text { Poisson's } \\
\text { ratio } \\
\text { (pa) }\end{array}$ & $\begin{array}{c}\text { Stretching } \\
\text { module }\end{array}$ & $\begin{array}{c}\text { Angle } \\
\text { Internal } \\
\text { friction }\end{array}$ & $\begin{array}{c}\text { Adhesion } \\
\text { (pa) }\end{array}$ & $\begin{array}{c}\text { Angle } \\
\text { Expansion }\end{array}$ & $\begin{array}{c}\text { Alpha } \\
\text { coefficient in } \\
\text { Riley dies }\end{array}$ \\
\hline soil & 1860 & 0.25 & $1.3 * 107$ & 33 & 1000 & 22.5 & 0.128 \\
\hline $\begin{array}{c}\text { Reinforced } \\
\text { concrete }\end{array}$ & 2400 & 0.15 & $2.12 * 1010$ & ----- & ---- & 15 & 1 \\
\hline $\begin{array}{c}\text { Reinforced } \\
\text { concrete }\end{array}$ & 2400 & 0.15 & $2.37 * 1010$ & ----- & ----- & 15 & 1 \\
\hline Rebar & 7850 & 0.3 & $109 * 2.059$ & ----- & ----- & ----- & ----- \\
\hline
\end{tabular}

\subsection{Soil Behavior Model}

The soil behavior model in this study is the Mohr-Coulomb model (figure1), which is used to model materials with the classic Mohr-Coulomb yield criterion. This model allows the materials to be hard and soft as isotropic. In the Mohr-Coulomb criterion, it is assumed that the yield occurs when the shear stress at any point in the material reaches a value that is linearly dependent on the normal stress on the same plate. The Columbus Mohr model is based on the drawing of Mohr's circles for the stress state in the maximum and minimum plate yields of the main stresses.

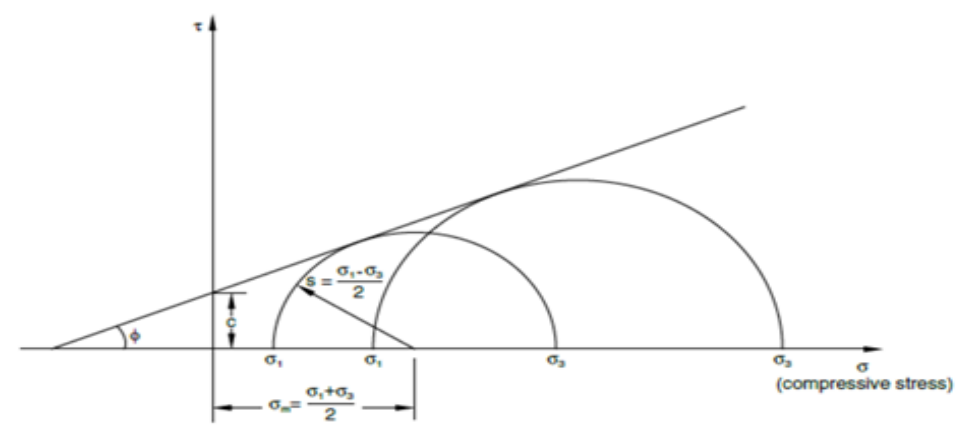

Figure1. Mohr-Coulomb submission model [30] 


\subsection{Concrete and Steel Plastic Specifications}

After reaching the yield point, the material's behavior goes out of line and more additional information is needed to model it. Information about the behavior of a substance is obtained from the tensile tests after the yield point. To model a material in limited deformation Plastic is needed to access this information. A very important issue in modeling the material in the plastic range is that in the tensile test the results obtained from the device are the stress and strain of engineering or the nominal material. As you know, the following relationships are used to convert nominal stress and strain to actual stress and strain. In order to introduce the plastic behavior of matter to the software, the actual stress and strain of the material must be entered [7].

$\varepsilon=\ln (1+\varepsilon 0)$

$\sigma=\sigma 0(1+\varepsilon 0)$

Where $\varepsilon 0$ and $\sigma 0$ are the nominal strain and stress, respectively, and $\varepsilon$ and $\sigma$ are the actual strain and stress, respectively. Due to this important point, the stresses and strains obtained from the A-III rebar tension tests must be converted to real stresses and strains. The actual stress-strain diagram of rebar A-III is given below [8]. According to the above point, the stresses and strains obtained from the tensile test have become real stresses and strains and are according to the table (table2) below.

Table2. Tension - Real strain of steel [8]

\begin{tabular}{|c|c|c|}
\hline plastic strain & strain & Stress(MPa) \\
\hline 0 & 0 & 0 \\
\hline 0 & 0.00269 & 538 \\
\hline 0.003942 & 0.006632 & 559 \\
\hline 0.027271 & 0.029961 & 631 \\
\hline 0.038735 & 0.041425 & 679 \\
\hline 0.057553 & 0.060243 & 753 \\
\hline 0.083318 & 0.086008 & 835 \\
\hline 0.10843 & 0.11112 & 878 \\
\hline 0.12947 & 0.13216 & 918 \\
\hline 0.15008 & 0.15277 & 960 \\
\hline 0.17359 & 0.17628 & 1005 \\
\hline 0.19005 & 0.19274 & 1022 \\
\hline 0.20303 & 0.20572 & 1035 \\
\hline
\end{tabular}

The first column of the table above shows real stresses and the second column shows real strains and the third column is the actual plastic strains. The actual plastic strains are also calculated from the following formula (reducing the yield strain from the actual strain).

eplastic $=\varepsilon$-Eyield

To enter the properties of steel plastic failure, the following methods have been used. We assign the values of stress and strain of plastic into the Mechanical / Plasticity / Plastic items to the rebar. The first column is set to define the yield stress values and the second column is the plastic strain values.

\subsection{Specifications of Concrete Plastic Failure}

Determining the nonlinear behavior of concrete is the most important step in numerical modeling of reinforced concrete structures. In ABAQUS finite Element software, nonlinear behavior of brittle materials can be done in three ways: described the crack model, the brittle fracture model and the concrete plastic damage model. Each of these models has advantages that can be used as needed [9]. Concrete damage plasticity model is the only model that can be used in both static and dynamic analysis. In this model, it is assumed that tensile and compressive fracture cracks are the two main aspects of the concrete rupture mechanism and for modeling the failure of brittle materials under cyclic loading alternating tension and pressure designed so that it is possible to recover hardness in It exists during round trips [26]. This model is used in all ABAQUS products for areas where concrete is under load. The basis of this behavioral model is assumed to be the same as the round damage coefficient. In this study, to determine the nonlinear behavior of concrete, a model of plastic concrete damage has been used. 


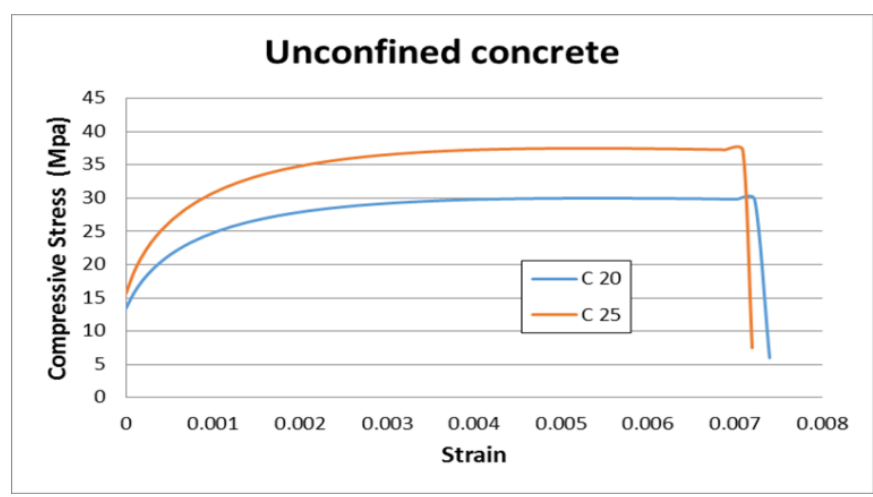

Figure2. Tension diagram - Concrete plastic strain [26]

A solid section for concrete was applied to the concrete section by the assign section. Also, sections were defined as truss by entering the cross-sectional area for rebar used in modeling and applied to the materials.

\subsection{Definition of Solver and Surfaces Reaction}

In the Assembly section, the parts were assembled side by side. The columns were spaced 19 meters apart. In the Step section, a Dynamic Explicit step is defined with a time of 40 seconds. In the interaction section, the reinforcement mesh was buried inside the concrete section with the embedded region order. The connection between the piles and the concrete bases was defined as a complete connection with the Tie command. The connection between the lower surface of the deck and the upper surface of the beams was also connected by the Tie command. Contact between other levels was defined by the create interaction command with a friction coefficient of 0.1 .

\subsection{Boundary Conditions}

In the LOAD section, the boundary conditions of the model were applied. Both sides of the bridge and the foundations of the bridge were accelerated by the Northridge earthquake.

\subsection{Mesh}

In the mesh section of the Abacus software, the models were modeled. The deck and bridge columns were modeled with a $0.5 \mathrm{~m}$ element size and an 8-node three-dimensional continuous element type with a reduced C3D8R integral. As mentioned, the C3D8R element is used for all concrete parts. This element is a three-dimensional element with eight nodes that uses the reduced integral method to solve integrals. The letter $\mathrm{C}$ indicates that this element belongs to the Continuum family. This element in each node has three degrees of freedom of displacement in the direction of the $\mathrm{X}, \mathrm{Y}$ and $\mathrm{Z}$ axes. This smaller element is also used to mesh the foundation. The T3 D2 two-node element is also used to element the reinforcement [10].

\subsection{Introducing the Reduced Integration Element}

Due to the problem of shear locking in Full integration elements, this group of elements should be used in loads with a minimum or zero bending. Therefore, it seems necessary to provide an alternative solution with the aim of analyzing bending problems. One of the existing suggestions is to use elements in which integration points are reduced and are known as reduced integration. Reduced integration elements have one less integration point in each direction, so linear order elements of this group use only one integration point in the middle. The following figure (figure 4) shows the placement of these points in linear and two-order elemental elements [11].
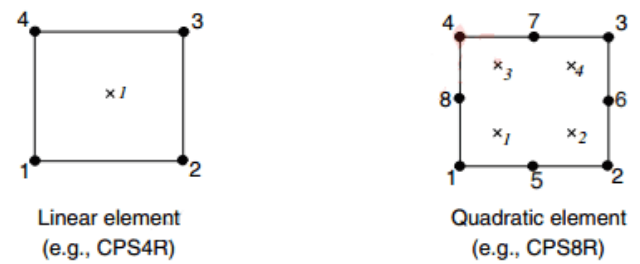

Figure3. Introduction of reduced integral element [29] 
To illustrate the point, consider a linear element in the reduced state that is subjected to pure bending: shear locking means changing the angle between the lines passing through the integration points, which causes the strain energy to change instead of bending. The shape is cut and, in simpler language, the element behaves more rigidly and the results are not reliable. However, in the figure above, where the problem-solving process in the integral method is reduced, the angles of the lines passing through the integral points do not change, which leads to reliable simulation and the results are based on reality [10].

\subsection{Soil Modeling}

The soil model with dimensions of $110 \times 50 \times 30(\mathrm{~m})$ was modeled as follows (figure 5) and the size of the element was $2.5,0.5$ and $1(\mathrm{~m})$ with the type of continuous element of 8 nodes with reduced integrated element.

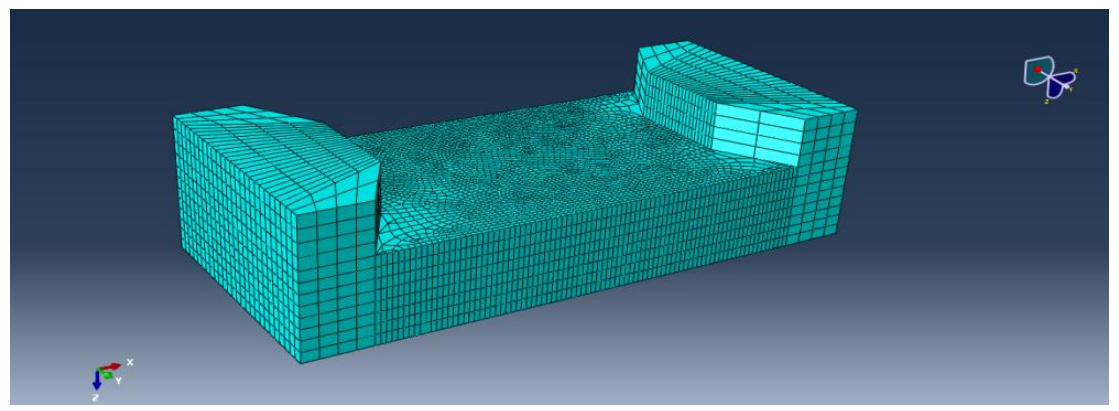

Figure4. Soil modeling in the studied model

In the interaction section, the piles were buried inside the soil. And the connection between the two sides of the bridge with soil was defined as a complete connection with the Tie order.

\subsection{Definition of the Action of Concrete and Rebar's}

For this modeling, we use the embedded region constraint. With this condition, we will be able to determine the tolerance level of a part of a model with the help of a host area (or the whole model) inside another part. The reinforcement was considered as a buried area in concrete [11].

\subsection{Choose the Right Solvent}

As mentioned earlier, the finite element method is a mathematical and numerical method for solving differential equations. To solve dynamic problems, two methods are used in analysis software: Implicit and explicit. The difference between Explicit and Implicit is in the mathematical method of solving the equation. Consider $\mathrm{t}$ for time and $\mathrm{t} \Delta$ for development time.

- In the Implicit method, the equation is solved for the time $t+t \Delta$, the state of the solution at the time $t$ $+\mathrm{t} \Delta$ is not yet known, and with initial guessing and using the Newton-Raphson method to solve the equation until a convergent answer is reached. Implicit always offers a sustainable solution, and it can be said that it is usually the best option for solving static or quasi-static problems. In this method, the set of system equations is solved directly, in other words, in this method, a stiffness matrix is formed for the whole structure and for each node the corresponding displacement is obtained and the solution is based on reversing the stiffness matrix. Therefore, the resolution time of this method will be longer than the explicit method. Instead, the results of the implicit method are more in line with reality than the explicit method.

In the Explicit method, the equation is solved using the current state of the problem (at time $t$ ) to determine the time $\mathrm{t}+\mathrm{t} \Delta$, the state of the problem at time $\mathrm{t}$ is known, and the stiffness matrix is known at this point. The equation is solved directly. The explicit method calculates the displacement of each node according to the acceleration of that node at each loading step. In this method, the effect of external forces on the object will be in the form of tension wave propagation and the problem will be solved dynamically, so if the wave velocity in the structure (same as the speed of sound) exceeds the software resolution speed, the solution errors and instability in the problem occurs. Therefore, the role of inertial forces in the obtained answers is very effective. The calculation method is such that it is not necessary to form a stiffness matrix for the whole structure. One of the advantages of the explicit method over the implicit method is the higher resolution speed in complex call issues. 
Another advantage of using this method is that it requires less storage space on the same issue than the implicit method on a computer. In this study, the analysis was performed as General-Dynamic, Explicit and with Fixed Mass Scaling technique. Since the scaling process is applied only once, at the beginning of the problem solving step, Fixed Mass Scaling is very efficient and optimal in terms of computational cost. [12].

\section{DISCUSSION}

In the analysis of the seismic behavior of a structure, the stimulus applied to the structure by the ground for the situation where the structure relies on hard ground and bedrock is the same stimulus that existed before the construction of the structure at that point, but if the structure Relying on soft soil, significant changes will occur in the seismic input of the structure. The results of this study express the effects of considering the interaction of soil and structure in a deep bridge foundation. The study of stresses, strains, displacement and acceleration of deck and comparison of these parameters with each other are described below.

\subsection{Investigating Tensions}

In the case of elements that are subjected to normal hybrid and shear stresses, it is possible to check whether the body has reached the yield point by using von Mises stress criterion. In the element in question, the principal stresses are calculated based on the Mohr's circle. If we put these principal stresses in the control relationship of von Mises, if the value of the stress of von Mises was less than the value of the yield stress, that is, failure does not occur, but if this stress was greater than the yield stress, it means that the element reaches the yield point. In finite element software such as Abacus, stress analysis usually uses von Mises stress to judge the stresses on matter. The maximum stress in this case is estimated at 4.13 MPa. Then von Mises examined while the bridge was located on the ground (taking into account the soil-foundation interaction). The maximum stress level in this case is estimated to be 23.63 (mega pascals). Comparing the amount of stress in the above two cases, it should be said that considering the interaction of soil and foundation has increased the maximum stress in the model by $644 \%$. In fact, comparing the results, it can be seen that the interaction of soil and structure has reduced the stresses on the deck and the foundations of the bridge and increased the amount of stress on the foundation and the pile group.

\subsection{Investigating Strains}

The maximum total strain rate was obtained in the case of considering the effects of interaction (0.000258) and without considering the effects of interaction (0.051). Therefore, it should be said that considering the effects of interaction has reduced the total strain by $2000 \%$ on the deck. In the stressstrain curve, before the elastic limit, the material strain is elastic and its deformation is recovered after loading. Thus, in the case Loading and unloading in this range, the material will return to its original length. If the load is more than elastic, a permanent deformation will remain in the material, which is called plastic strain. By examining the results, it can be seen that the amount of plastic strain in the deck has been obtained in the case of considering the interaction of soil and foundation (0.0163) and without considering the interaction of soil and foundation (3.59x10-6). The amount of plastic strain on the deck when considering the interaction of soil and structure is $4540 \%$ higher than that of soil and foundation interaction. Therefore, considering the interaction of soil and structure has increased the ductility of the deck. By examining the results, it can be seen that the amount of plastic strain in the bases of the bridge has been obtained in the case of considering the interaction of the soil and the foundation of 0.002381 and without considering the interaction of the soil and the foundation of 0.00010388 . The amount of plastic strain in the bases in the case of considering the interaction of soil and structure is $2200 \%$ more than the case where the interaction of soil and foundation is not considered. Therefore, considering the interaction of soil and structure has increased the formability of foundations.

\subsection{Check for Displacement}

Examining the contour of the bridge displacement in both cases with and without considering the interaction of soil and foundation, it can be seen that the maximum amount of displacement in the bridge considering soil and foundation interaction is $345(\mathrm{~mm})$ without considering soil and foundation interaction (7.008 millimetre). Therefore, considering the effects of soil and foundation 
interaction increases the displacement of bridge. The amount of displacement depends on the type of soil, soil stiffness, structure and loads. Considering the interaction of soil and structure increases the displacement in the bridge by $492 \%$.

\subsection{Acceleration of the Bridge Deck}

In the following figures, the acceleration of the bridge deck at the time of the Northridge earthquake is presented in both cases with (figure6) and without (figure7) considering the interaction of the soil and the structure.

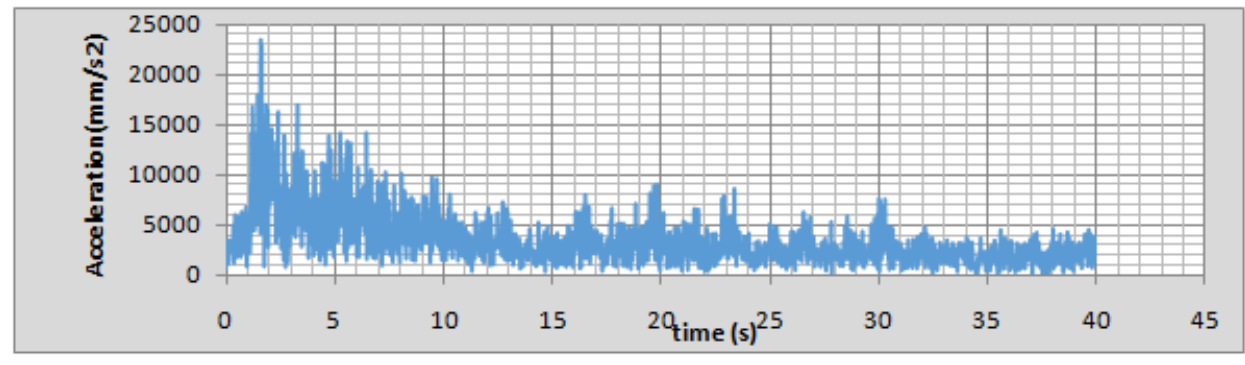

Figure5. Bridge deck acceleration considering interaction effects

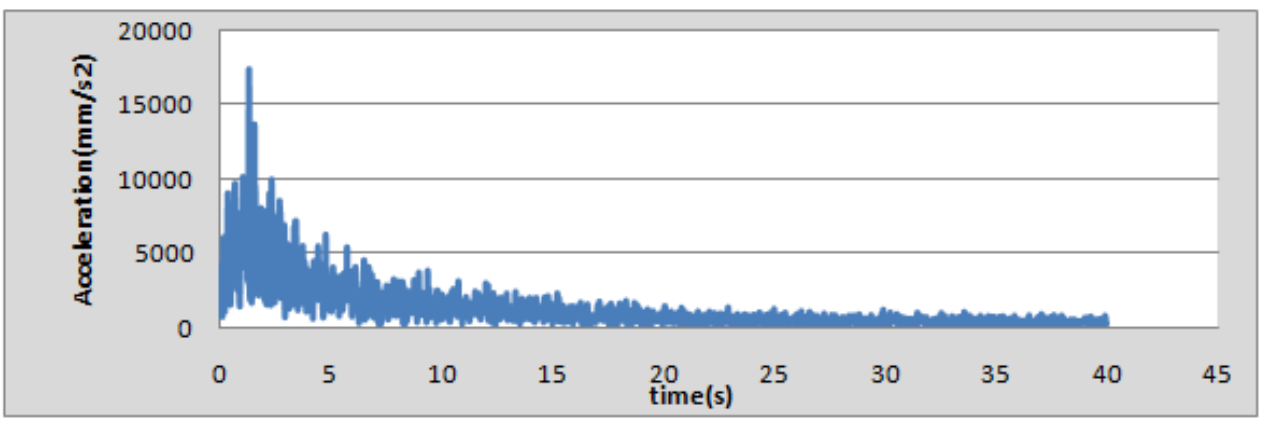

Figure6. Deck acceleration without considering the effects of interaction

Considering the above figures, it should be said that the maximum acceleration of the bridge deck in the mode considering the interaction effects is more than the case where the interaction effects are not considered. The maximum acceleration of the bridge deck is $23480(\mathrm{~mm} / \mathrm{s} 2)$ in the case of interaction effects and $17187(\mathrm{~mm} / \mathrm{s} 2)$ in the case of non-interaction effects. In fact, considering the interaction effects of soil and structure increases the bridge deck acceleration by $73 \%$.

\section{CONCLUSiON}

Comparing the amount of stress in the above two cases, it should be said that considering the interaction of soil and foundation has increased the maximum stress of the whole bridge complex in the studied model. However, more detailed studies have shown that the interaction of soil and structure has reduced stress on the deck and bridge columns and increased the amount of stress on the foundation and the pile group. The maximum amount of total strain when considering the effects of interaction has been obtained 0.000258 without considering the interaction effects of was 0.0517 . Therefore, it should be said that considering the interactive effects has reduced the total strain on the deck. The amount of plastic strain in the deck is obtained in the case of considering the interaction of the soil and the foundation of 0.0163 and without considering the interaction of the soil and the foundation of 3.59x 10-6. The amount of plastic strain on the deck when considering the interaction of soil and structure is more than the case where soil and foundation interaction is not considered. Therefore, considering the interaction of soil and structure has increased the ductility of the deck. The amount of plastic strain at the bridge pier is obtained in the case of considering the interaction of soil and foundation (0.002381) and without considering the interaction of soil and foundation (0.0001038). The amount of plastic strain in the piers in the case of considering the interaction of soil and structure is more than the case where the interaction of soil and foundation is not considered. Therefore, considering the interaction of soil and structure has increased the consistency of foundations. The maximum amount of displacement in the bridge is obtained by considering the interaction of soil and foundation $345(\mathrm{~mm})$ without considering the interaction of soil and foundation 
$0.788(\mathrm{~mm})$. Therefore, considering the effects of soil and foundation interaction will increase the displacement of bridge. The amount of displacement depends on the type of soil, soil stiffness, structure, and loads. The maximum acceleration of the bridge deck in the mode considering the interactive effects is more than the case where the interactive effects are not considered. The maximum acceleration of the bridge deck is $23480(\mathrm{~mm} / \mathrm{s} 2)$ in the case of interactive effects and $17187(\mathrm{~mm} / \mathrm{s} 2)$ in the case of non-interactive effects. In the dynamic analysis of structures, it is often assumed that the soil is under a solid foundation and that the reactionary effects between the soil and the structure are ignored. In this case, the structure's response is only affected by the structural properties of the structure itself, and soil flexibility has no effect on the structure's response. In this fact, the response of the structure is affected by the dynamic properties of the soil, the foundation and the structure, which is inconsistent with the assumption that the soil under the foundation is rigid. Soil-structure interaction occurs due to the passage of earthquake waves through the soil-structure system. Therefore, it is clear that it will be necessary to consider the effect of soil-structure action to achieve real response and predict structural behavior.

\section{Suggestions For Future RESEARCH}

In future research, the effect of the length and diameter of the pile on the displacement and stresses, strains and accelerations of the bridge deck can be compared in two cases with and without considering the interactive effects. Also, the effect of different soil types in terms of geotechnical parameters on the response rate of the structure, taking into account the effects of the interaction between the structure and the soil, is another topic that can be examined.

\section{REFERENCES}

[1] Soltani, Haniyeh and Fereshteh Emami, 2009, Seismic Behavior of Concrete Reinforced Reinforced Concrete Bridges Based on Hard Clay Bed, Under Earthquake Seizures Considering Soil and Structure Interaction, 3rd International Conference on Applied Research in Structural Engineering and Management Manufactured, Tehran, Sharif University of Technology

[2] Siahi, Mohsen and Javad Esfandiari, 2009, The Effect of Interaction Effects between Soil and Structure and Intermediate on Static and Dynamic Response of Structures, 3rd International Conference on Applied Research in Structural Engineering and Construction Management, Tehran, Sharif University of Technology

[3] Askari Fork, Saeed; Ehsan Mohtashami and Amirsalar Mehrabad, 2009, A Study of the Impact of Soil and Structure Interaction on Models of Large-Scale Air Wind Turbines, 11th National Congress of Civil Engineering, Shiraz, Shiraz University

[4] Shayanfar, Mohsen Ali and Ali Shokrian, 2009, Evaluation of the effect of soil and structure interaction on the fragility curve of three-span concrete bridge, 6th National Conference on Applied Research in Civil Engineering, Architecture and Urban Management, Tehran - Khajeh Nasir al-Din Tusi Industrial University, Khajeh Nasir al-Din University of Technology Gray.

[5] Asghari, Vahid and Rasoul Jani, 2009, Numerical Survey of Seismic Behavior of the Collection Group, Considering the Effects of Structure-Soil-Collection Interaction, Quarterly Journal of Civil Engineering and Environment, Tabari University.

[6] Eftekhari, Seyed Mosayeb and Adel Beit Safi, 1397, The Effect of Soil Cutting Parameters on Soil and Structure Interaction in Concrete Structures Fourth Edition of Standard 2800, National Conference on Fundamental Research in Civil Engineering, Architecture and Urbanism, Tehran, Ouj Higher Education Institute.

[7] wahalathantri, b.l., thambiratnam, d.p., chan, t.h.t., \& fawzia, s. "a material model for flexural crack simulation in reinforced concrete elements using abaqus". in proceedings of the first international conference on engineering, designing and developing the built environment for sustainable wellbeing, queensland university of technology, brisbane, qld, pp. 260-264.2011.

[8] Sarvari, Younes "Mechanical Software Reference Training Reference", Simulation and Finite Element, 2016.

[9] The Pacific Earthquake Engineering Research Center official website: http: peer.berkeley.edu.

[10] Nielson, B. (2003) "Bridge Seismic Fragility-Functionality Relationships: A Requirement for Loss Estimation in Mid- America", School of Civil and Environmental Engineering, Georgia Institute of Technology, Atlanta, GA.

[11] Fowler (1925). The Concise Oxford Dictionary. Oxford University Press. p. 102 
[12] Sadoughi Shabestari, Araz and Solmaz Sadoughi Shabestari, 2016, Investigation of creep effects in bridge analysis with beam and concrete slab deck, First National Conference on Applied Research in Civil Engineering (Structural Engineering and Construction Management), Tehran, Sharif University of Technology.

[13] John P. Wolf, (1985), Dynamic SoiI-Structure Interaction.

[14] Ohnaka, M. (2013). The Physics of Rock Failure and Earthquakes. Cambridge University Press. p. 148.

[15] TC/FHWA (1983) "Seismic Retrofitting Guidelines for Highway Bridges",Report ATC-6-2, Applied Technology Council, Redwood City, California. Also Published by Federal Highway Administration as Report FHWA/RD-83/007.

[16] Chen, W. F., Duan, L. (1999). Bridge Engineering Handbook, CRC Press, Florida.

[17] ASHTO (1996) Standard Specifications for Highway Bridges, 16th ed., American Association of State Highway and Transportation Officials, Washington, D.C.

[18] Hsu, Y. T., Fu, C. C. (2004) "Seismic Effect on Highway Bridges in Chi Chi Earthquake", ASCE Journal of Performance of Constructed Facilities, Vol. 18, No. 1, pp. 1-7.

[19] Wolf, J. P. (1985). Dynamic Soil-Structure Interaction. Prentice-Hall, Inc., Englewood Cliffs, New Jersey.

[20] Carder, D. R. and Barker, K. J., "Performance of a single row of spaced bored piles to stabilise a Gault Clay slope on the M25", TRL Report-627, Transport Research Laboratory, Crowthorne, Berkshire, UK, (2005).

[21] Randolph, M. F., "Design Methods for Pile Groups and Piled Rafts", State of the art report, 13th Int'l Conf. Soil Mech. Foundn. Engng., New Delhi,Vol.5, pp. 61-88, (1994).

[22] International Institute of Seismology and Earthquake Engineering, http://www.iiees.ac.ir

[23] Dassault Systèmes official website : http://www.abaqus.net/

[24] Daryl L. Logan (2011). A first course in the finite element method. Cengage Learning

[25] abaqus 6.10 analysis user's manual volume III.

[26] Kausel, E. (2010). Early history of soil-structure interaction. Soil Dynamics and Earthquake Engineering, $30(9), 822-832$.

[27] Fitzgerald, B., \& Basu, B. (2016). Structural control of wind turbines with soil structure interaction included. Engineering Structures, 111, 131-151.

[28] Isbiliroglu, Y., Taborda, R., \& Bielak, J. (2015). Coupled soil-structure interaction effects of building clusters during earthquakes. Earthquake Spectra, 31(1), 463-500.

[29] Abaqus/CAE webpage, getting start with ABAQUS/CAE

[30] Menétrey, Ph., and K. J. Willam, "Triaxial Failure Criterion for Concrete and its Generalization," ACI Structural Journal, vol. 92, pp. 311-318, May/June 1995.

Citation: Moein Zargar, et.al, "The Soil-Pile Dynamic Interaction Effect on Bridges with Slab-Beam Deck by Using Finite Element Method”, International Journal of Constructive Research in Civil Engineering, 6(3), pp. 11-20 DOI: https:// doi.org/10.20431/2454-8693.0603002.

Copyright: (C) 2020 Authors, this is an open-access article distributed under the terms of the Creative Commons Attribution License, which permits unrestricted use, distribution, and reproduction in any medium, provided the original author and source are credited. 